\title{
Evaluation of performance indicators for canal command area of Samrat Ashok Sagar Project Vidisha district M.P.
}

Shiv Singh Basediya, S. K. Pyasi and R. N. Shrivastava

Received : 28.01.2018; Revised : 10.03.2018; Accepted : 22.03.2018

See end of the Paper for authors' affiliation

Correspondence to :

Shiv Singh Basediya Department of Soil and Water Engineering, Jawaharlal Nehru Krishi Vishwa Vidyalaya, Jabalpur (M.P.) India
- ABSTRACT : The existing irrigation system of right bank canal including the canal water distribution, irrigation supplied, crop yield, water used and water productivity was evaluated on the basis on Nelson's parameters. These indicators was found as Tail end supply ratio: 0.71, delivery timeliness ratio: 0.75 carrying capacity ratio: 0.79 and fee collection performance: 0.35 for Canal Command Area of Samrat Ashok Sagar Project Vidisha district M.P. Tail end ratio value 0.71 indicated that water supply in the head and tail was almost in satisfactory range. It was also observed that tail end water supply was sufficient for 80 days only out of 112 days of canal operation. Delivery timeliness ratio $(0.75)$, carrying capacity ratio $(0.79)$, poor structure ratio $(0.00)$, fee collection(0.35), Manpower numbers ratio (0.003), sustainability of irrigated area ratio (1.16) and area infrastructure ratio (301.62) were calculated tail end supply ratio was not found within the preference range this indicates that amount water reaching to tail end is not satisfactory and requires proper planning. Similarly fee collection ratio was also found poor and needs improvement The values of other water delivery indicators was found within reference range and hence, declared satisfactory.

- KEY WORDS : Performance indicator, Canal irrigation performance, Water management, Water productivity, Water user association

- HOW TO CITE THIS PAPER : Basediya, Shiv Singh, Pyasi, S.K. and Shrivastava, R.N. (2018). Evaluation of performance indicators for canal command area of Samrat Ashok Sagar Project Vidisha district M.P. Internat. J. Agric. Engg., 11(1) : 244-248, DOI: 10.15740/HAS/IJAE/11.1/ 244-248. 